Medical
Epigenetics

\title{
Epigenetic Regulation of Infant Neurobehavioral Outcomes
}

\author{
Corina Lesseur ${ }^{\mathrm{a}}$ Alison G. Paquette ${ }^{\mathrm{a}}$ Carmen J. Marsit ${ }^{\mathrm{a}-\mathrm{c}}$ \\ a Department of Pharmacology and Toxicology, and b Section of Biostatistics and \\ Epidemiology, Department of Community and Family Medicine, Geisel School of Medicine \\ at Dartmouth, Hanover, N.H., and ' Norris Cotton Cancer Center, Lebanon, N.H., USA
}

\section{Key Words}

Neurobehavior - Epigenetics - Neonatal Intensive Care Unit Network Neurobehavioral Scales . Placenta $\cdot$ Autism $\cdot$ DNA methylation

\begin{abstract}
During fetal development and early infancy, environmental signals can induce epigenetic changes that alter neurobehavioral development and later-life mental health. Several neurodevelopmental genetic diseases influence epigenetic regulatory genes and genomic imprinting. Recently, brain epigenetic marks have been involved in idiopathic neurodevelopmental disorders, including autism spectrum disorders. The placenta is an important regulator of the intrauterine environment that links maternal and fetal nervous systems. Placental epigenetic signatures have been associated with the neurodevelopment of healthy newborns quantified through the Neonatal Intensive Care Unit Network Neurobehavioral Scales (NNNS). Associations have been observed for DNA methylation of genes involved in cortisol (NR3C1, HSD11B), serotonin (HTR2A), and metabolic (LEP) pathways. Dysregulation of imprinted genes and microRNAs has also been associated with neurobehavior assessed by NNNS. Further analysis is needed to characterize the mechanisms by which the epigenome influences neurodevelopment and the connection between this dysregulation and mental health disorders. In the future, epigenetic marks could serve as functional biomarkers of mental health and cognitive function.




\section{Introduction}

The developmental origins of health and disease hypothesis proposes that environmental cues during fetal development and early infancy induce adaptive responses that can influence later-life disease susceptibility [1]. Populations exposed to prenatal famine show an increased risk of later-life mental outcomes, specifically schizophrenia, depression, addiction and dysregulation of stress response, suggesting that intrauterine conditions program later-life mental health [2]. This early-life programming requires plasticity, thus epigenetic mechanisms have been proposed as molecular mediators because these integrate genetic and environmental signals with the control of gene expression [3].

Epigenetics is the study of heritable but feasibly environmentally modifiable control of gene expression potential without DNA sequence changes [4]. The major systems of epigenetic regulation include DNA methylation, genomic imprinting, non-coding RNAs and histone modifications. DNA methylation is the best-characterized epigenetic mark and involves the addition of a methyl group to cytosines usually within $\mathrm{CpG}$ dinucleotides that in promoters frequently results in gene silencing [4]. Epigenetic regulation is essential during development when somatic and germ cells experience a global epigenetic remodeling that regulates cell and tissue differentiation $[5,6]$. The quality of the environment during this and other sensitive periods could alter this epigenetic reprogramming. Rodent studies have shown that maternal behavior in early life influences offspring behavior during adulthood through epigenetic deregulation of NR3C1 and other loci [7-9]. This suggests that during intrauterine and early postnatal life, epigenetic programming occurs that has long-term influences on mental health (fig. 1).

In this review, we outline the evidence relating epigenetic variation and neurodevelopmental diseases and discuss epigenetic marks in the placenta, a crucial organ for intrauterine development, and their role in infant neurodevelopmental outcomes.

\section{Role of Epigenetics in Neurodevelopmental Disease}

The significance of epigenetics in neurodevelopment is illustrated in genetic conditions that influence epigenetic regulatory genes and affect cognitive functions [10]. Rett syndrome is a neurodevelopmental condition associated with autism spectrum disorder (ASD), and is

Fig. 1. Diagram of principal factors influencing infant neurobehavior. Maternal and paternal genetics influence neurological, cognitive and behavioral outcomes. The in utero and early-life environment can also influence these outcomes through epigenetic mechanisms. The placenta regulates the in utero environment, and its epigenetic profiles can contribute to infant neurobehavior.

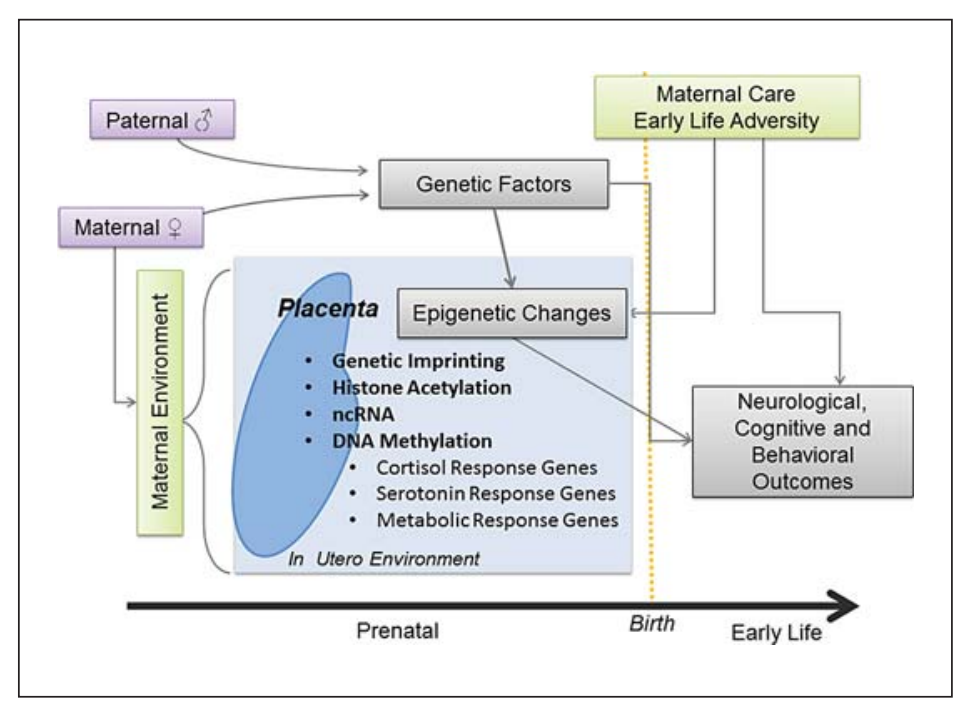


caused by genetic mutations in the X-linked MECP2 [11]. MeCP2 is a chromatin-associated protein that binds to methylated DNA, is highly expressed in the brain and is required for neuronal maturation. Loss or aberrant MeCP2 function leads to epigenetic deregulation and impaired synaptic function $[10,12]$. Similarly, genomic imprinting disorders of 15q11-13 lead to Angelman syndrome and Prader-Willi syndrome, neurodevelopmental pathologies with structural and functional brain changes [13-15]. Imprinted genes are expressed in a parent-of-origin-specific manner because DNA methylation silences the other allele [16]. A large proportion of imprinted genes are expressed in the brain, and imprinting disorders frequently exhibit neurodevelopmental delay [13]. Although most Angelman syndrome and Prader-Willi syndrome cases are caused by genetic changes, in some cases, loss of gene function is attributable to an imprinting defect or epimutation [17]. Moreover, 15q11-13 duplications are frequent cytogenetic abnormalities in ASD [18].

The majority of neurodevelopmental disorders, including ASD, cannot be directly associated with specific genetic changes, but have complex genetic and environmental influences contributing to disease [18]. Since epigenetic mechanisms integrate these signals, a number of studies suggest that idiopathic neurodevelopmental disorders may result from epigenetic dysregulation of neurological pathways. Most human studies of neurobehavioral disease and epigenetics (table 1) [19-27] compare epigenetic profiles between ASD cases and controls in post mortem brain samples, a highly relevant tissue but not readily available. This limitation imposes cross-sectional study designs and reduces sample sizes. Thus, when selecting tissues for epigenetic studies of human neurobehavior, it is important to consider the high tissue specificity of epigenetic marks, the relevance to neural development and the accessibility for prospective studies.

\section{Placental Epigenetics and Infant Neurobehavior}

During intrauterine life, the placenta is the essential regulator of the fetal environment [28] and has been described as a third brain linking the mother and the infant [29]. Recent evidence suggests similarities between neuronal and placental DNA methylation profiles in areas associated with neuronal development genes [30]. In order to study epigenetic changes that occur during prenatal development and their relationship with infant neurobehavioral outcomes, we have explored placental epigenetic marks as functional biomarkers of the in utero environment in a large population-based cohort of healthy term infants: the Rhode Island Child Health Study (RICHS). We assessed newborn neurobehavior using the Neonatal Intensive Care Unit Network Neurobehavioral Scales (NNNS), a comprehensive evaluation of neurobehavioral performance, including neurologic and behavioral measures and signs of stress [31]. Profiles of neurobehavior derived through NNNS have previously shown to predict neurodevelopmental and cognitive performance in childhood [32].

Maternal cortisol influences the development of the fetal HPA axis and is metabolized through the placenta [33]. Thus, changes in the placental cortisol metabolism may alter infant neurobehavioral outcomes. We have analyzed epigenetic changes in the cortisol response genes HSD11B2 and NR3C1 within the RICHS cohort. HSD11B2 inactivates cortisol by metabolizing it to cortisone, protecting the infant from excess glucocorticoids [34]. HSD11B2 promoter methylation was associated with decreased quality of movement [35]. In an expanded study, we observed an interaction between maternal anxiety and HSD11B2 methylation that contributed to infant hypotonia [36]. NR3C1 encodes the glucocorticoid receptor, is expressed in the placenta and is involved in the metabolism of maternal cortisol. NR3C1 placental methylation is positively associated with infant attention and quality of movement NNNS scores and negatively associated with stress abstinence scores [37]. In a larger study, 
Table 1. Human studies of epigenetics and neurobehavior

Gene(s), epigenetic Major findings

change

First author, year of publication

Epigenetics and neurobehavioral disease

MECP2 MECP2 promoter hypermethylation in the prefrontal cortex of male ASD cases.

DNA methylation Lower brain MECP2 expression in ASD cases.

MECP2 $\quad$ Increased methylation of a transition area (upstream of $M E C P 2$ ) in the frontal cerebral

Nagarajan

et al. [19], 2006

Nagarajan MECP2 methylation is locus-specific rather than global X chromosome changes.

DNA methylation

\begin{tabular}{ll}
\hline OXTR & OXTR hypermethylation in the blood and temporal cortex of ASD \\
DNA methylation & Decreased OXTR expression in the temporal cortex of ASD cases.
\end{tabular}

et al. [20], 2008

Differentially methylated genes in the blood of ASD cases enriched for transcription,

nervous system development and cell death/survival. RORA and BCL-2 exhibited decreased

protein expression in tissue arrays (cerebellum and frontal cortex) in ASD cases.

$8.1 \mathrm{~K} \mathrm{CpG}$ island array (HCGI8.1K).

DNA methylation

\begin{tabular}{ll}
\hline Genome-wide scan & $\begin{array}{l}\text { Subset of ASD cases exhibited H3K4me3 spreading into nucleosomes in the prefrontal } \\
\text { cortex. Identification of 711 loci with an altered H3K4me3 signal in the brain of ASD cases }\end{array}$
\end{tabular}

compared to that of controls. H3K4me3 peaks enriched in genes implicated in

Histone methylation neurodevelopmental disease.

Aberrant H3K4 methylation at a specific TSS is a predictor of transcriptional dysregulation.

EN-2

DNA and histone

$E N-2$ promoter hypermethylation in the cerebellar cortex associated with ASD,

Gregory et al.

[21], 2009

Nguyen et al.

[22], 2010

Shulha et al.

[23], 2012

methylation is positively correlated with $E N-2$ expression.

Decreased histone H3K27 in the $E N-2$ promoter in ASD cases.

3 DMRs in the temporal cortex:

PRRT1

PRRT1 (3'UTR) hypomethylation in ASD cases,

TSPAN32/C11 orf21

Near ZFP57

TSPAN32/C11 orf21 hypomethylation in ASD cases,

SDHAP3 near ZFP57 hypermethylated in ASD cases,

DNA methylation 1 DMR cerebellum SDHAP3 hypermethylated in ASD cases.

SHANK3 SHANK3 hypermethylation in the cerebellum and cerebral cortex of ASD cases compared to

DNA methylation that of controls. Altered expression, an alternative splicing of SHANK3 isoforms in brain tissue.

DRD4 and 5-HTT

Cord blood DNA methylation of DRD4 and 5-HTT regions are negatively associated with

2014

the ADHD symptom score at age 6

van Mil et al.

[27], 2014

Placental epigenetics and newborn neurobehavior

HSD11B2 Inverse association between placental HSD11B2 methylation and quality of

DNA methylation movement scores in RICHS newborns.

Pregnancy anxiety and placental HS11B2 methylation (CpG4) interaction influence hypotonicity in RICHS infants.

NR3C1 Higher NR3C1 placental promoter methylation is associated with higher quality of

DNA methylation movement scores and lower infant attention scores in RICHS newborns.

Potential interaction between methylation and genotype on infant attention score.

Pregnancy depression and placental NR3C1 methylation (CpG2) interaction

influences self-regulation, hypotonicity and lethargy in RICHS infants.

HTR2A Higher HTR2A placental methylation is associated with lower quality of movement

DNA methylation and higher infant attention scores in RICHS newborns.

LEP

Higher LEP promoter placental methylation is associated with membership in a NNNS

DNA methylation neurobehavioral profile marked by increased lethargy and hypotonicity and reduced risk of membership in a profile with opposite characteristics in RICHS newborns.

Expression of Placental imprinted gene expression classes are associated with quality of movement

22 imprinted genes and handling in RICHS newborns.

Expression of Increased miR-16 placental expression is associated with reduced attention, increased

6 placental miRNAs miR-146a and miR-182 placental expression is associated with increased quality of

movement in RICHS newborns.
Marsit et al.

[35], 2012

Conradt et al.

[36], 2013

Bromer et al.

[37], 2013

Conradt et al.

[36], 2013

Paquette

et al. [43], 2013

Lesseur et al.

[47], 2014

Marsit et al.

[56], 2012

Maccani et al.

[51], 2013

MECP2 = Methyl CpG-binding protein 2; OXTR = oxytocin receptor; RORA = RAR-related orphan receptor A; BCL-2 = B-cell CLL/ lymphoma 2; H3K4me3 = trimethylation of lysine 4 of histone 3; $E N-2$ = engrailed homeobox 2; DMR = differentially methylated region; PRRT1 = proline-rich transmembrane protein 1; TSPAN32 = tetraspanin 32; C11orf21 = chromosome 11 open reading frame 21; ZFP57 = zinc finger protein; SDHAP3 = succinate dehydrogenase complex, subunit A, flavoprotein pseudogene 3; SHANK3 = SH3 and multiple ankyrin repeat domains 3; DRD4 = dopamine receptor D4; SLC6A4 = solute carrier family 6; HSD11B2 = hydroxysteroid (11-beta) dehydrogenase 2; NR3C1 = glucocorticoid receptor; $H T R 2 A=$ hydroxytryptamine (serotonin) receptor $2 \mathrm{~A}$; $L E P=$ leptin; TSS $=$ transcriptional start site. 
we observed an interaction between maternal depression and NR3C1 methylation on infant hypotonicity, lethargy and self-regulation [36]. Both HSD11B2 and NR3C1 promoter methylation are negatively associated with expression $[35,37]$, suggesting that infants with a higher methylation of these genes are exposed to increased cortisol. In humans, the cortisol response pathway influences infant cognitive development and physical maturation [38, 39]. Altered placental cortisol response may change infant neuromuscular and stress responses, as reflected in the infant's attention, stress-abstinence and quality of movement scores. Further analysis of other genes involved in cortisol response, such as FKBP5, is needed to fully understand the contribution of these epigenetic changes to infant neurobehavior.

Cortisol response and serotonergic tone are intimately linked, and serotonin can stimulate the HPA axis [34]. During fetal development, serotonin is important for the development of brain circuits [40], and the placenta acts as a transient source of serotonin during the early development [41]. Infants who experienced maternal depression in utero had decreased promoter methylation of the serotonin receptor SLC6A4 in their blood [42], but we did not find associations between placental promoter methylation of SLC6A4 and infant neurobehavioral outcomes within the RICHS cohort (unpublished data). Methylation of the serotonin receptor HTR2A was positively associated with NNNS attention scores and negatively associated with quality of movement [43]. This study provided evidence for epigenetics as a potential regulator of the placental serotonin response pathway, which influences behavioral outcomes. More research is needed to determine if other genes in this pathway are epigenetically regulated.

Rodent studies have linked the adipokine leptin (LEP) with neurodevelopment; leptindeficient mice (ob/ob) display brain abnormalities and decreased locomotor activity [44]. Leptin is epigenetically regulated and produced by the placenta $[45,46]$. Recently, we detected an association between higher $L E P$ promoter methylation and increased odds of membership in a neurobehavioral profile characterized by lethargy and hypotonicity and with reduced odds of membership in a profile with opposite characteristics [47]. These observations were significant only in males and consistent with a marked negative correlation between methylation and $L E P$ gene expression that was absent in placentas from females. These are the first results that link an energy-homeostasis gene with human neurobehavior and resemble the phenotype of ob/ob mice. Future research is needed to assess if epigenetic marks in other metabolic genes can influence neurobehavior.

MicroRNAs (miRNAs) post-transcriptionally target mRNAs and induce gene silencing, regulating a substantial amount of the mammalian genome [48]. miRNAs have been linked to placental functions and pathology and to neuronal survival and differentiation during development $[49,50]$. We assessed placental expression of 6 miRNAs and their relationship to neurobehavior in the RICHS study [51]. Increases in miR-16 were associated with reduced attention scores, and increased miR-146a and miR-182 expression was associated with increased quality of movement scores. Some of the targets of these miRNAs are involved in the regulation of the serotonin [52], NFK $\beta$ [53] and reward pathways [54]. This could help explain our observations regarding infant neurobehavior.

Imprinted gene expression is abundant in human placenta and is involved in growth and neural development $[13,55]$. We observed associations between expression profiles of 22 placental-imprinted genes and quality of movement and handling scores of RICHS infants [56]. Quality of movement was associated with a decreased expression of the imprinted genes involved in neurological and motor functions during development, including MEG3, HOXA11 and HOXD10. We also observed a high degree of correlation in the expression of adjacent imprinted genes, suggesting that in utero exposures produce coordinated expression changes and/or disrupt imprinting within control regions. Further research is required to determine the role of epigenetic marks in imprinted genes and infant neurobehavior. 


\section{Future Directions}

The field of neurobehavioral epigenetics is growing, with human studies complementing animal models. The human environment is multifaceted, and the fetus is exposed to nonspecific stressors, which are difficult to capture in laboratory conditions. The laboratory environment may induce epigenetic alterations independently of experimental conditions, confounding analysis. However, there are limitations to the observations made from human population studies. Epigenetic changes are tissue-specific [57]. The placenta is a relevant and accessible tissue for infant neurobehavioral studies [30], but we cannot definitely assess if these epigenetic patterns are conserved in brain tissue. These studies are also limited by their observational nature; we cannot establish mechanisms based on observed associations, and we cannot presently assess the prognostic value of neurobehavioral outcomes observed at birth. Most studies have used candidate gene approaches of targets known to be important in the developing brain, and we encourage validation of findings from candidate gene studies in different populations. However, this has a limited scope in complex neurobehavioral phenotypes, highlighting the need for epigenome-wide, agnostic analyses to identify novel genes that contribute to infant neurobehavior.

A number of neurobehavioral diseases exhibit sex differences in their prevalence and onset, including autism, ADHD and affective disorders [58]. Placental epigenetic marks also exhibit sexual dimorphism [47, 59-61], which could influence these neurobehavioral differences. More research is needed to define sexually dimorphic epigenetic patterning in autosomal loci and their potential role in infant neurobehavioral outcomes.

DNA sequence variation also exerts effects on epigenetic signatures across the genome [62]. Thus, it is important to consider possible contributions of single nucleotide polymorphisms to epigenetic regulation of neurobehavior. It has been suggested that individuals may be able to adapt to deleterious polymorphisms through epigenetic changes, which may explain the inability of these polymorphisms alone to predict disease [63]. In particular, monozygotic twins represent a desirable population to study because of reduced genetic confounding. Differential epigenetic patterning in combination with genetic factors may help explain differences in behavioral responses.

As our understanding of epigenetic changes and their role in newborn behavior increases, they could serve as biomarkers of neurobehavioral risk, facilitating early screening. In neurobehavioral diseases that manifest in early childhood, such as autism and ADHD, prompt interventions are important to improve long-term mental health $[64,65]$. Future advancements may move this field beyond risk assessment to identification of prognostic biomarkers to evaluate response to therapy. The brain epigenome exhibits plasticity throughout life [66], and response to cognitive therapies alters gene expression $[67,68]$, which may be driven by epigenetic changes. Tracking responses to cognitive interventions through epigenetic markers could provide a quantitative assessment of therapeutic response. Pharmacologic agents that alter gene expression through epigenetic changes are established treatments for some psychiatric and neurologic conditions. This is the case for valproic acid, and it has been proposed that it could be used to correct epigenetic changes in cognitive disorders [69, 70]. Maternal cognitive intervention may induce epigenetic effects in offspring, as epigenetic changes have been observed in children born to mothers who underwent bariatric surgery [71]. More groundwork is needed to understand the normal epigenome, the consequences of its deregulation and the connection with mental health disorders before these tools can be used as functional biomarkers. 


\section{Acknowledgments}

This work was supported by NIH-NIMH R01MH094609, NIH-NIEHS R01ES022223 and NIH-NIEHS P01 ES022832/EPA RD83544201.

\section{References}

$>1$ Gluckman PD, Hanson MA, Spencer HG, Bateson P: Environmental influences during development and their later consequences for health and disease: implications for the interpretation of empirical studies. Proc Biol Sci 2005;272:671-677.

-2 Räikkönen K, Pesonen A-K, Roseboom TJ, Eriksson JG: Early determinants of mental health. Best Pract Res Clin Endocrinol Metab 2012;26:599-611.

-3 Gluckman PD, Hanson MA, Pinal C: The developmental origins of adult disease. Matern Child Nutr 2005;1: 130-141.

4 Jaenisch R, Bird A: Epigenetic regulation of gene expression: how the genome integrates intrinsic and environmental signals. Nat Genet 2003;33:245-254.

5 Reik W: Stability and flexibility of epigenetic gene regulation in mammalian development. Nature 2007;447: 425-432.

6 Cantone I, Fisher AG: Epigenetic programming and reprogramming during development. Nat Struct Mol Biol 2013;20:282-289.

7 Weaver IC, Cervoni N, Champagne FA, D’Alessio AC, Sharma S, Seckl JR, Dymov S, Szyf M, Meaney MJ: Epigenetic programming by maternal behavior. Nat Neurosci 2004;7:847-854.

8 Sasaki A, de Vega WC, McGowan PO: Biological embedding in mental health: an epigenomic perspective. Biochem Cell Biol 2013;91:14-21.

$\rightarrow 9$ Roth TL, Lubin FD, Funk AJ, Sweatt JD: Lasting epigenetic influence of early-life adversity on the BDNF gene. Biol Psychiatry 2009;65:760-769.

10 Tsankova N, Renthal W, Kumar A, Nestler EJ: Epigenetic regulation in psychiatric disorders. Nat Rev Neurosci 2007;8:355-367.

-11 Amir RE, Van den Veyver IB, Wan M, Tran CQ, Francke U, Zoghbi HY: Rett syndrome is caused by mutations in X-linked MECP2, encoding methyl-CpG-binding protein 2. Nat Genet 1999;23:185-188.

12 Guy J, Cheval H, Selfridge J, Bird A: The role of MeCP2 in the brain. Annu Rev Cell Dev Biol 2011;27:631-652.

-13 Wilkinson LS, Davies W, Isles AR: Genomic imprinting effects on brain development and function. Nat Rev Neurosci 2007;8:832-843.

14 Yamada K, Matsuzawa H, Uchiyama M, Kwee IL, Nakada T: Brain developmental abnormalities in Prader-Willi syndrome detected by diffusion tensor imaging. Pediatrics 2006;118:e442-e448.

15 Williams CA: Neurological aspects of the Angelman syndrome. Brain Dev 2005;27:88-94.

16 Temple IK, Clayton-Smith J, Mackay DJ: Imprinting Disorders of Early Childhood in Epigenetic Epidemiology. New York, Springer, 2012, pp. 137-160.

17 Buiting K, Groß S, Lich C, Gillessen-Kaesbach G, El-Maarri O, Horsthemke B: Epimutations in Prader-Willi and Angelman syndromes: a molecular study of 136 patients with an imprinting defect. Am J Hum Genet 2003;72: 571-577.

18 Schanen NC: Epigenetics of autism spectrum disorders. Hum Mol Genet 2006;15:R138-R150.

19 Nagarajan RP, Hogart AR, Gwye Y, Martin MR, LaSalle JM: Reduced MeCP2 expression is frequent in autism frontal cortex and correlates with aberrant MECP2 promoter methylation. Epigenetics 2006;1:e1-e11.

-20 Nagarajan RP, Patzel KA, Martin M, Yasui DH, Swanberg SE, Hertz-Picciotto I, Hansen RL, Van de Water J, Pessah IN, Jiang R, Robinson WP, LaSalle JM: MECP2 promoter methylation and X chromosome inactivation in autism. Autism Res 2008;1:169-178.

-21 Gregory SG, Connelly JJ, Towers AJ, Johnson J, Biscocho D, Markunas CA, Lintas C, Abramson RK, Wright HH, Ellis P, Langford CF, Worley G, Delong GR, Murphy SK, Cuccaro ML, Persico A, Pericak-Vance MA: Genomic and epigenetic evidence for oxytocin receptor deficiency in autism. BMC Med 2009; 7:62.

-22 Nguyen A, Rauch TA, Pfeifer GP, Hu VW: Global methylation profiling of lymphoblastoid cell lines reveals epigenetic contributions to autism spectrum disorders and a novel autism candidate gene, RORA, whose protein product is reduced in autistic brain. FASEB J 2010;24:3036-3051.

23 Shulha HP, Cheung I, Whittle C, Wang J, Virgil D, Lin CL, Guo Y, Lessard A, Akbarian S, Weng Z: Epigenetic signatures of autism: trimethylated H3K4 landscapes in prefrontal neurons. Arch Gen Psychiatry 2012;69:314-324.

-24 James SJ, Shpyleva S, Melnyk S, Pavliv O, Pogribny IP: Complex epigenetic regulation of engrailed-2 (EN-2) homeobox gene in the autism cerebellum. Transl Psychiatry 2013;3:e232.

25 Ladd-Acosta C, Hansen KD, Briem E, Fallin MD, Kaufmann WE, Feinberg AP: Common DNA methylation alterations in multiple brain regions in autism. Mol Psychiatry 2013, Epub ahead of print.

26 Zhu L, Wang X, Li XL, Towers A, Cao X, Wang P, Bowman R, Yang H, Goldstein J, Li YJ, Jiang YH: Epigenetic dysregulation of SHANK3 in brain tissues from individuals with autism spectrum disorders. Hum Mol Genet 2014;23:1563-1578. 
van Mil NH, Steegers-Theunissen RP, Bouwland-Both MI, Verbiest MM, Rijlaarsdam J, Hofman A, Steegers EA, Heijmans BT, Jaddoe VW, Verhulst FC, Stolk L, Eilers PH, Uitterlinden AG, Tiemeier H: DNA methylation profiles at birth and child ADHD symptoms. J Psychiatr Res 2014;49:51-59. Maccani MA, Marsit CJ: Epigenetics in the placenta. Am J Reprod Immunol 2009;62:78-89. Yen SS: The placenta as the third brain. J Reprod Med 1994;39:277-280.

-30 Schroeder DI, Blair JD, Lott P, Yu HO, Hong D, Crary F, Ashwood P, Walker C, Korf I, Robinson WP, LaSalle JM: The human placenta methylome. Proc Natl Acad Sci USA 2013;110:6037-6042.

31 Lester BM, Tronick EZ: The neonatal intensive care unit network neurobehavioral scale procedures. Pediatrics 2004;113:641-667.

-32 Liu J, Bann C, Lester B, Tronick E, Das A, Lagasse L, Bauer C, Shankaran S, Bada H: Neonatal neurobehavior predicts medical and behavioral outcome. Pediatrics 2010;125:e90-e98.

-33 Davis EP, Sandman CA: The timing of prenatal exposure to maternal cortisol and psychosocial stress is associated with human infant cognitive development. Child Dev 2010;81:131-148.

34 Lester BM, Conradt E, Marsit CJ: Epigenetic basis for the development of depression in children. Clin Obstet Gynecol 2013;56:556-565.

35 Marsit CJ, Maccani MA, Padbury JF, Lester BM: Placental 11-beta hydroxysteroid dehydrogenase methylation is associated with newborn growth and a measure of neurobehavioral outcome. PloS One 2012; 7:e33794.

-36 Conradt E, Lester BM, Appleton AA, Armstrong DA, Marsit CJ: The role of DNA methylation of NR3C1 and $11 \beta$-HSD2 and exposure to maternal mood disorder in utero on newborn neurobehavior. Epigenetics 2013; 8:1321-1329.

-37 Bromer C, Marsit CJ, Armstrong DA, Padbury JF, Lester B: Genetic and epigenetic variation of the glucocorticoid receptor (NR3C1) in placenta and infant neurobehavior. Dev Psychobiol 2013;55:673-683.

-38 Davis EP, Sandman CA: The timing of prenatal exposure to maternal cortisol and psychosocial stress is associated with human infant cognitive development. Child Dev 2010;81:131-148.

39 Ellman LM, Schetter CD, Hobel CJ, Chicz-Demet A, Glynn LM, Sandman CA: Timing of fetal exposure to stress hormones: effects on newborn physical and neuromuscular maturation. Dev Psychobiol 2008;50:232-241.

40 Deneris ES, Wyler SC: Serotonergic transcriptional networks and potential importance to mental health. Nat Neurosci 2012;15:519-527.

41 Bonnin A, Goeden N, Chen K, Wilson ML, King J, Shih JC, Blakely RD, Deneris ES, Levitt P: A transient placental source of serotonin for the fetal forebrain. Nature 2011;472:347-350.

42 Devlin AM, Brain U, Austin J, Oberlander TF: Prenatal exposure to maternal depressed mood and the MTHFR C677T variant affect SLC6A4 methylation in infants at birth. PloS One 2010;5:e12201.

43 Paquette AG, Lesseur C, Armstrong DA, Koestler DC, Appleton AA, Lester BM, Marsit CJ: Placental HTR2A methylation is associated with infant neurobehavioral outcomes. Epigenetics 2013;8:796-801.

44 Bouret SG: Neurodevelopmental actions of leptin. Brain Res 2010;1350:2-9.

45 Gambino YP, Maymó JL, Pérez Pérez A, Calvo JC, Sánchez-Margalet V, Varone CL: Elsevier Trophoblast Research Award lecture: molecular mechanisms underlying estrogen functions in trophoblastic cells - focus on leptin expression. Placenta 2012;33(suppl):S63-S70.

46 Bouchard L, Thibault S, Guay SP, Santure M, Monpetit A, St-Pierre J, Perron P, Brisson D: Leptin gene epigenetic adaptation to impaired glucose metabolism during pregnancy. Diabetes Care 2010;33:2436-2441.

-47 Lesseur C, Armstrong DA, Murphy MA, Appleton AA, Koestler DC, Paquette AG, Lester BM, Marsit CJ: Sexspecific associations between placental leptin promoter DNA methylation and infant neurobehavior. Psychoneuroendocrinology 2014;40:1-9.

-48 Friedman RC, Farh KK-H, Burge CB, Bartel DP: Most mammalian mRNAs are conserved targets of microRNAs. Genome Res 2009;19:92-105.

49 Morales-Prieto DM, Ospina-Prieto S, Schmidt A, Chaiwangyen W, Markert UR: Elsevier Trophoblast Research Award lecture: origin, evolution and future of placenta miRNAs. Placenta 2014;35(suppl):S39-S45.

50 Fiore R, Siegel G, Schratt G: MicroRNA function in neuronal development, plasticity and disease. Biochim Biophys Acta 2008;1779:471-478.

51 Maccani MA, Padbury JF, Lester BM, Knopik VS, Marsit CJ: Placental miRNA expression profiles are associated with measures of infant neurobehavioral outcomes. Pediatr Res 2013;74:272-278.

52 Baudry A, Mouillet-Richard S, Schneider B, Launay JM, Kellermann O: miR-16 targets the serotonin transporter: a new facet for adaptive responses to antidepressants. Science 2010;329:1537-1541.

53 Hou J, Wang P, Lin L, Liu X, Ma F, An H, Wang Z, Cao X: MicroRNA-146a feedback inhibits RIG-I-dependent type I IFN production in macrophages by targeting TRAF6, IRAK1, and IRAK2. J Immunol 2009;183:2150-2158.

54 Gerdjikov TV, Giles AC, Swain SN, Beninger RJ: Nucleus accumbens PKA inhibition blocks acquisition but enhances expression of amphetamine-produced conditioned activity in rats. Psychopharmacology 2007;190: 65-72.

55 Frost JM, Moore GE: The importance of imprinting in the human placenta. PLoS Genet 2010;6:e1001015.

56 Marsit CJ, Lambertini L, Maccani MA, Koestler DC, Houseman EA, Padbury JF, Lester BM, Chen J: Placentaimprinted gene expression association of infant neurobehavior. J Pediatr 2012;160:854-860.e2.

57 Jones PA, Takai D: The role of DNA methylation in mammalian epigenetics. Science 2001;293:1068-1070.

58 Viveros M-P, Mendrek A, Paus T, Lopez Rodriguez AB, Marco EM, Yehuda R, Cohen H, Lehrner A, Wagner E: A comparative, developmental and clinical perspective of neurobehavioral sexual dimorphisms. Front Neurosci 2012;6:84. 
59 Gabory A, Roseboom TJ, Moore T, Moore LG, Junien C: Placental contribution to the origins of sexual dimorphism in health and diseases: sex chromosomes and epigenetics. Biol Sex Differ 2013;4:5.

-60 Boks MP, Derks EM, Weisenberger DJ, Strengman E, Janson E, Sommer IE, Kahn RS, Ophoff RA: The relationship of DNA methylation with age, gender and genotype in twins and healthy controls. PloS One 2009; 4:e6767.

-61 El-Maarri O, Becker T, Junen J, Manzoor SS, Diaz-Lacava A, Schwaab R, Wienker T, Oldenburg J: Gender specific differences in levels of DNA methylation at selected loci from human total blood: a tendency toward higher methylation levels in males. Hum Genet 2007;122:505-514.

-62 Schalkwyk LC, Meaburn EL, Smith R, Dempster EL, Jeffries AR, Davies MN, Plomin R, Mill J: Allelic skewing of DNA methylation is widespread across the genome. Am J Hum Genet 2010;86:196-212.

63 Lester BM, Marsit CJ, Conradt E, Bromer C, Padbury JF: Behavioral epigenetics and the developmental origins of child mental health disorders. J Dev Orig Health Dis 2012;3:395-408.

64 Chronis AM, Jones HA, Raggi VL: Evidence-based psychosocial treatments for children and adolescents with attention-deficit/hyperactivity disorder. Clin Psychol Rev 2006;26:486-502.

65 Moree BN, Davis Iii TE: Cognitive-behavioral therapy for anxiety in children diagnosed with autism spectrum disorders: Modification trends. Res Autism Spectr Disord 2010;4:346-354.

-66 LaSalle JM, Powell WT, Yasui DH: Epigenetic layers and players underlying neurodevelopment. Trends Neurosci 2013;36:460-470.

-67 Moustafa AA: Increased hippocampal volume and gene expression following cognitive behavioral therapy in PTSD. Front Hum Neurosci 2013;7:747.

-68 Atkinson D, Iannotti S, Cozzolino M, Castiglione S, Cicatelli A, Vyas B, Mortimer J, Hill R, Chovanec E, Chiamberlando A, Cuadros J, Virot C, Kerouac M, Kallfass T, Krippner S, Frederick C, Gregory B, Shaffran M, Bullock M, Soleimany E, Rossi AC, Rossi K, Rossi E: A new bioinformatics paradigm for the theory, research, and practice of therapeutic hypnosis. Am J Clin Hypn 2010;53:27-46.

69 Narayan P, Dragunow M: Pharmacology of epigenetics in brain disorders. Br J Pharmacol 2010;159:285-303.

70 Peedicayil J: Epigenetic drugs in cognitive disorders. Curr Pharm Des 2013, Epub ahead of print.

-71 Guénard F, Deshaies Y, Cianflone K, Kral JG, Marceau P, Vohl M-C: Differential methylation in glucoregulatory genes of offspring born before vs. after maternal gastrointestinal bypass surgery. Proc Natl Acad Sci USA 2013; 110:11439-11444. 